\title{
Toward an urban transport sustainability index: an European comparison
}

\author{
Pietro Zito • Giuseppe Salvo
}

Received: 15 April 2011 /Accepted: 19 September 2011 /Published online: 29 October 2011

(C) The Author(s) 2011. This article is published with open access at SpringerLink.com

\begin{abstract}
Introduction The aim of paper is to cluster policies of sustainable mobility in order to define an essential set of specific Transport Performance Indicators (TPI). TPIs are standardized measures suitable for analysis in order to appraise the feasibility of a transport policy or an infrastructural project. Data collection of TPIs is a crucial phase, but data detection and monitoring are not standardized at the city level. Thus, there is no a standard for data collection and storing, this aspect makes much difficult to compare different city contexts. This issue is critical and bounds the analysis of built scenarios. A standardized set of transport performance indicators becomes, hence, essential for monitoring the implemented policies.

Methodology and results The paper answers to some of these questions, providing a specific set of sustainable and transport performance indicators to evaluate effects of policy measures. Furthermore, it shows a comparative analysis of different European cities in terms of development, sustainability and infrastructures, by using transport performance indicators. A Normalized Transport Sustainability Index has been built using identified TPIs, in order to measure and hence to compare the whole sustainability of adopted policies in different urban areas. The same NTSI allows to appraise the expected results and thus to tune the policy measures.

Conclusion We can affirm that an high value of sustainability is associated, in general, to small-medium cities in term both population and urban area; nevertheless, for large cities, the adoption of policy measures, from a side, to control the urban sprawl, from the other side, to manage the
\end{abstract}

P. Zito $(\bowtie) \cdot$ G. Salvo

Department of Energy, University of Palermo,

Palermo, Italy

e-mail: pietro.zito@unipa.it urban transport demand with an adequate public transport development allows to achieve a more sustainable mobility.

Keywords Transport performance indicators · Transport sustainability index · Urban sustainable mobility

\section{Introduction}

In the last years, warnings were more frequently launched by the scientific community about the actual use of energy resources and their progressive exhaustion, the effects on the environment caused by economic, social and industrial choices, in particular in terms of pollution. In this case, climate changes are among the most marked effects, often perceived even by not expert citizens. Obviously, such inputs must be taken into account by policy makers that participate to the debate on concerted strategies and actions in order to reduce GHG emissions.

From one side, the scientific community shows hypothetical global scenarios that redesign a lifestyle of people heavily conditioned by effects of climate change, whether actions for $\mathrm{CO}_{2}$ emission reduction in atmosphere would be put in force now; such actions will have to become more drastic every time that delays on actions occur. Many of such actions could heavily influence the lifestyle of citizens, habits, up to change over time, on large scale, the industrial, economic and social structure on which world economy and the society are based. Nevertheless, the scientific viewpoint suffers of uncertainty related to long period forecasting of possible future scenarios, therefore damage estimations are affected by uncertainty and inaccuracy. From the other side, the task of policy maker is to manage the community and activities related to it. Her/his decisions are often related to short term and are strongly influenced by social and economic context. 


\subsection{Review of literature}

Nowadays there is however the awareness that only technological changes and more efficiency on fuels and vehicles are not enough to reach sustainable environmentally transport targets required to stabilize the $\mathrm{CO}_{2}$ in atmosphere in next future [37]. These targets will be reached whether marked behavioral change in citizens related to travel choices occur. The sustainable mobility approach requires actions to reduce the need to travel (less trip; i.e. by ICT, internet shopping, teleworking and so on), to encourage modal shift (i.e. by transport policy measures), to reduce trip length (i.e. by land use and urban planning) and to encourage greater efficiency in the transport system [3].

Many other studies confirm abovementioned statement. Shiftan et al. [33] identified policies for a sustainable transport system in Tel-Aviv Metropolitan Area by scenarios and Delphi expert based survey. Findings in desired scenario were a strong development of public transport and a coordination between spatial development and transport system, high parking fees, congestion pricing and maintaining the functional role of Central Business District Area. Whereas Rajan [30] pointed out that in order to meet stringent emission targets technology and pricing policies may have to be supplemented by strategies to change life-styles and land uses in ways that effectively reduce car dependence. Akerman and Hojer [1] showed that a target level for sustainable GHG emissions cannot be reached only by relying on technology but also it would be possible with a combination of ICT services and urban planning. Hickman and Banister [19] studied a backcasting approach to develop alternative scenarios related to different policy measures. Most findings were that a given reduction target can be achieved by a combination of strong behavioral changes and technological innovations. Bristow et al. [6] showed how even dramatic technological advance cannot meet more stringent targets for carbon reduction in the absence of a considerable behavioral change. Same conclusions are also highlighted in Yang et al. [43].

\subsection{Sustainable mobility policy at national and urban level}

The sustainable development or sustainable city is the most important element when attempting to identify climatefriendly travel scenarios in the cities. The most common definition of sustainable development is that used by the Bruntland Commission: "Sustainable development seeks to meet the needs and aspirations of the present without compromising the ability to meet those of the future." (Report of the World Commission on Environment and Development., General Assembly Resolution 42/187, 11 December 1987). This implies the harmonization, jointly, of three issues: economic growth, protection of environmental resources and social equality.

There is no universally accepted definition of sustainable transportation. However, a broader definition of sustainable transportation-"satisfying current transportation and mobility needs without compromising the ability of future generations to meet their own needs". The criteria for the sustainable transportation thus can be: 1) the extent of satisfying transportation demand, the technical and commercial feasibility of the transportation technology, etc. (i.e. economic objectives); 2) the production and regeneration functions, etc. (i.e. environmental objectives); and 3) cultural richness, institutional factors, social equity, etc. (i.e. social objectives).

European projects (i.e. EU Transport GHG: Routes to 2050? 2009) [32] aim to stimulate a debate about the actions that need to be taken in the medium- to long-term (particularly between 2020 and 2050) to reduce greenhouse gas emissions from the transport sector in the EU. Another, the TREMOVE project [39] is a transport and emissions simulation model developed for the European Commission. The model estimates the transport demand, the modal split, the vehicle stock turnover, the emissions of air pollutants and the welfare level under different policy scenarios. Both projects are implemented to national and European context, and policy scenarios are related to European policies (as euro 5 and euro 6 emission standards for cars, euro 4 emission standards for heavy duty vehicles, fuel efficiency improvements beyond the 2008/2009 voluntary objectives of the car industry, etc.).These are very different from local policies where effects are bounded in the local area and can bring to an effective behavioral change in travel choices and life style habits through "push and pull" policy measures.

Among projects on this topic, CATCH [9], Vibat for London [40] are those implemented in local areas (i.e. cities of London and Delhi). The sustainable mobility approach requires clear and innovative thinking about city futures in terms of the reality (what is already there) and the desirability (what we would like to see), and the role that transport can (and should) play in achieving sustainable cities. This balances the requirements along the physical dimensions (urban structure and traffic) against the social dimensions (people and proximity) [18].

Municipalities and governments need to have effective assessment tools, to implement their policies/actions, being so able to make informed choices in order to change the citizens' behavior. Naturally politicians reflect the point of view of people and their priority on environmental issues "perception of facts". There is a need to provide new and better understandings of rising mobility and the consequences for individuals, and society. The role of internet as information and marketing channel are of growing impor- 
tance. As urban planning has become increasingly complex, decision support tools are essential to help to achieve the overall objective of sustainability.

There are difficulties, on a theoretical as well as on a practical level, related to the implementation of policy measures in the city context. There is the need to provide new and more effective assessment tools to policy makers able to address immediate and integrated solutions to city issues. In such context, a standardized set of performance indicators would allow to analyze quantitatively the effects of adopted policy measures. Nowadays, there is no a standardized assessment framework model able to test of policy measures effects on urban areas. Further, every application is site dependent and uses specific set of indicators. The lack of homogeneity in detection, measure, store and monitoring of standardized performance indictors often does not permit to compare different city contexts. In other words, the objective of the our analysis is:

- to provide a specific set of sustainable and transport performance indicators to evaluate effects of policy measures;

- to provide a comparative analysis of different cities in terms of development, sustainability and infrastructures, by using transport performance indicators.

The paper is so structured: Section 2 describes the analysis of sustainable transport policies, Section 3 shows the cluster of policies; Section 4 shows the transport performance indicators; Section 5 the sustainable transport index and finally the conclusions are summarized.

\section{Analysis of sustainable mobility policies in urban areas}

Each citizen is daily subjected to external factors of various nature, coming from surrounding environment which strongly influence his/her travel decision. Some of these factors have a direct relation on travel behaviour related to the mobility, conditioning travel choices both on short term (i.e. mode and/or route choice etc.) and on medium/long term (i.e. origin of trip, etc.). Instead other factors involve in wider manner the lifestyle of every citizen and in indirect way on mobility (i.e. changes on land use, economic development, etc.). Choices of the single citizen or actions put in force by the policy maker related to climate friendly travel choices are the object of this analysis.

Recent research has shown that any single policy instrument cannot achieve the sustainability. Policy strategies employing several instruments are needed to be successful. The use of formal models and optimization methods is suggested to be used to identify the best performing strategy. According to literature, key factors that influence the development of transportation are classified by following categories:

1. Technology: technology can contribute to sustainable transportation by improving vehicle efficiency or by substituting trip through ICT.

2. Economic development: transportation projects are highly sensitive to economic changes.

3. Spatial and land-use patterns: the travel demand and transportation system are influenced by the size of the urban area, building density, activities location.

4. Government policy: Authorities are strongly involved in transportation development.

5. Social and behavioral trends: individual behavior is a combination of habits, practical and emotional considerations. Thus, social values and norms may greatly affect the transportation choice of individuals.

The Fourth Assessment Report on Climate Change [24] highlights how global GHG emissions due to human activities have grown with an increase of $70 \%$ between 1970 and 2004. Carbon dioxide (CO2) is the most important anthropogenic GHG. Its annual emissions have grown between 1970 and 2004 by about $80 \%$, from 21 to 38 gigatonnes (Gt), and represented $77 \%$ of total anthropogenic GHG emissions in 2004. The largest growth in GHG emissions between 1970 and 2004 has come from energy supply, transport and industry, while residential and commercial buildings, forestry (including deforestation) and agriculture sectors have been growing at a lower rate (Fig. 1).

There is high agreement and much evidence that with current climate change mitigation policies and related sustainable development practices, global GHG emissions will continue to grow over the next few decades [24]. Some key technologies, for transport sector can be pointed out in: more fuel-efficient vehicles; hybrid vehicles; cleaner diesel vehicles; biofuels; modal shifts from road transport to rail and public transport systems; second generation biofuels; higher efficiency aircraft; advanced electric and hybrid vehicles with more powerful and reliable batteries; whereas for policy measures: mandatory fuel economy; biofuel blending and $\mathrm{CO} 2$ standards for road transport; taxes on vehicle purchase, registration, use and motor fuels; road and parking pricing, non-motorised transport (cycling, walking); land-use and transport planning; influence mobility needs through land-use regulations and infrastructure planning; investment in attractive public transport facilities and non-motorised forms of transport.

In Europe according to the Report on Transport Emission Trends (EEA, report n.5/2008), between 1990 and 2006, GHG emissions from transport (all modes of transport) increased by 

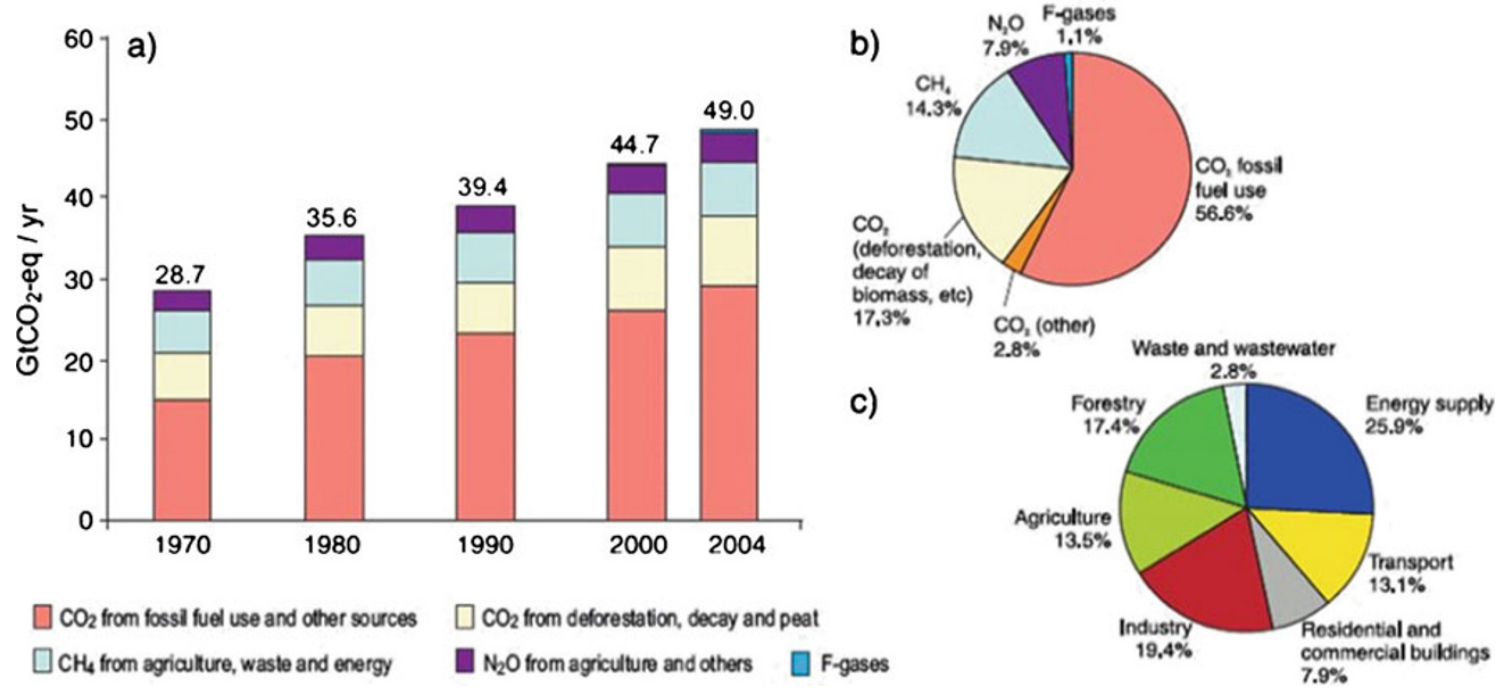

Fig. 1 Global annual GHG emissions from 1970 to 2004 (Source: [24])

26\%. They increased between 2000 and 2006 by $5 \%$. Furthermore between 2005 and 2006, GHG emissions from transport increased by $0.4 \%$. Emissions from transport are projected to increase from 1990 levels in all EU-15 Member States except in Germany. Ireland and Portugal even project an increase of more than $200 \%$. In the EU-15, emissions in 2010 are projected to remain at 2006 levels with the existing measures. Emissions could be reduced to $+19 \%$ above 1990 levels with the implementation of additional measures. Between 1990 and 2006, CO2 emissions from road transport increased by $25 \%$. They increased by $4 \%$ between 2000 and 2006. Road transport represents $93 \%$ (in 1990 as well as in 2006) of total transport $\mathrm{CO} 2$ emissions (international aviation excluded) (Fig. 2).

The European Union strategy to reduce $\mathrm{CO}_{2}$ emissions from passenger cars and improve fuel economy aimed at delivering an average $\mathrm{CO}_{2}$ emission value for new passenger cars equal to $120 \mathrm{~g} \mathrm{CO}_{2} / \mathrm{km}$. It was meant to help the $\mathrm{EU}$ meet its commitments under the Kyoto Protocol, and reduce the EU dependency on imported oil supplies. In order to meet these targets, voluntary commitments by the European, Japanese and Korean automobile manufacturers' associations
(ACEA, JAMA, KAMA) were made, where the automobile industry committed itself to reach average specific $\mathrm{CO} 2$ emissions of $140 \mathrm{~g} \mathrm{CO} 2 /$ vehicle-km for new passenger cars by 2008 (ACEA) and 2009 (JAMA/KAMA).

For U.S. Environmental Protection Agency [15], transportation activities accounted for $28 \%$ of U.S. greenhouse gas emissions in 2007. The largest sources of transportation GHGs in 2007 were passenger cars (33\%), light duty trucks, which include sport utility vehicles, pickup trucks, and minivans $(28 \%)$, freight trucks $(21 \%)$ and commercial aircraft (8\%). From 1990 to 2007, transportation emissions rose by $29 \%$ due, in large part, to increased demand for travel and the stagnation of fuel efficiency across the U.S. vehicle fleet. The number of vehicle miles traveled by light duty motor vehicles (passenger cars and light-duty trucks) increased 40\% from 1990 to 2007, as a result of a confluence of factors including population growth, economic growth, urban sprawl, and low fuel prices over much of this period.

Carbon dioxide (CO2) emissions released from fossil fuel consumption in Asia increased from 2136 million tons in 1980 to 7692 million tons in 2005, with an average annual growth rate of $5.3 \%$ [21]. China and India, are responsible for
Fig. 2 Sector shares of total greenhouse gases in 1990 and 2006 in the EU-15 (source: [14])
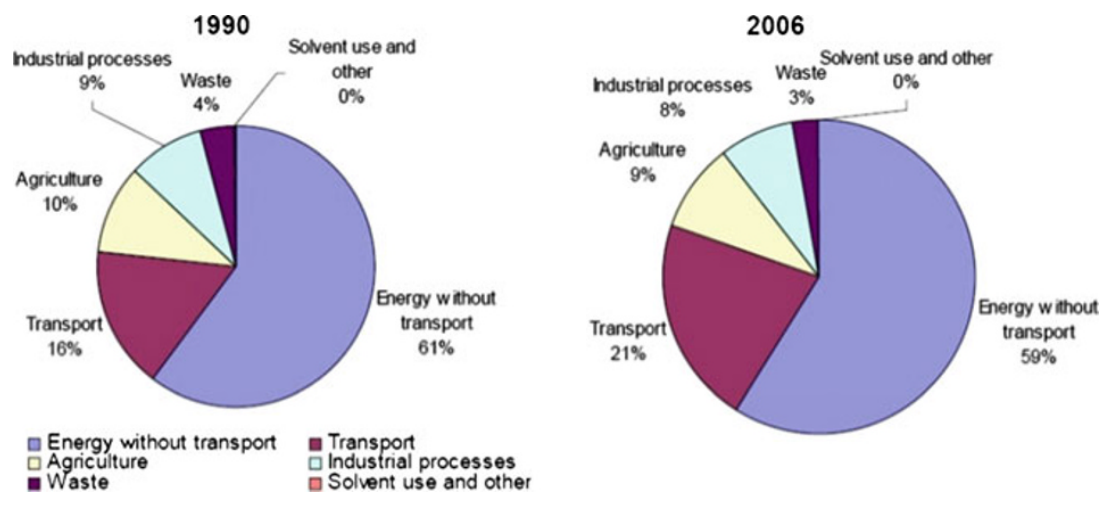
approximately $80 \%$ of the region's total $\mathrm{CO} 2$ emissions, feature a relatively low share of emissions from the transport sector in their national $\mathrm{CO} 2$ emissions. The per capita economic growth effect and the population growth effect are found to be primarily responsible for driving transport sector CO2 emissions growth [38]. Das and Parikh [12], analyzed the urban transportation system and its energy-environment implications for two mega cities of India, Delhi and Mumbai. This study examines the implications of a range of economic growth scenarios on travel demand, energy demand and emissions. It shows that despite similar population and higher per capita GDP, due to the higher share of road public transport and suburban railway system, Mumbai transport consumes less energy and emissions than Delhi. This picture may change in the future with the introduction of metro in Delhi, but basic differences remain even in 2020, perhaps also due to the different urban design.

Another interesting comparison among cities concerns the Vibat Project for London and Delhi. Hickman et al. [18] show a comparison between London and Delhi and the conclusion risen from these applications (Fig. 3).

The successful implementation of vehicle efficiencies and alternative fuels to the mass market is critical. Thus a behavioural change hence becomes important-aimed at reducing the growth in travel, particularly car-based travel. Some behavioural change policy areas appear to be very important, but are underplayed in policy terms. These include pricing regimes (perhaps via a carbon tax or fuel duty) and urban structure, as an important enabler of carbon efficient travel in the form of public transport, walking and cycling and short distance trips. These packages are particularly important in both cities - achieving ambitious targets mean that a much greater share of trips need to be made by non-car modes [18].

The first evidence is that there are very few studies/ projects for cities and in general for local areas, we can cite Y. Shiftan et al. [33], Das and Parikh [12], Vibat London
[40], INTRA-SIM Oxfordshire [23]. Obviously policies adopted in a given geographical context (i.e. European) are different from policies adopted in local context in term of economic resources, time horizon, effects and objectives.

The paper of Hickman and Banister [19] investigates how UK may reduce transportation greenhouse gas emissions. Wang et al. [41] reviews all recent environmental policies in China relating to the automobile industry and employs a scenario analysis to estimate different emissions inventories for different development strategies. Yang et al. [43] investigates how California may reduce $\mathrm{CO} 2$ emissions. Bristow et al. [6] develops pathways to low carbon land-based passenger transport in Great Britain by 2050 . Wang et al. [41] have proposed a CO2 mitigation scenarios in China's road transport sector. Shiftan et al. [33] suggests and uses a scenario approach to explore the future development of the Tel-Aviv Metropolitan Area (TAMA). Akerman and Hojer [1] proposed an image of a sustainable transport system for Sweden. Using the COPERT III program, Soylu [34] calculated Turkish road transport emissions. Das and Parikh [12] developed transport scenarios in two metropolitan cities in India: Delhi and Mumbai. Rajan [30] reviews the prospects for emissions reductions in the US passenger transport sector and the technical, economic, social, and political barriers to developing policies that focus solely on technology or pricing.

\section{Cluster of policies}

Both land use and transportation are part of a complex system as the urban one, that is subject to external influences. Each component of the system constantly evolves, due to changes in technology, policy, economics, demographics and even culture/values, as a result of the many decisions made by residents, businesses and governments. The main focus is:
Fig. 3 Comparison Per Capita Transport CO2 Emissions (source: [18])

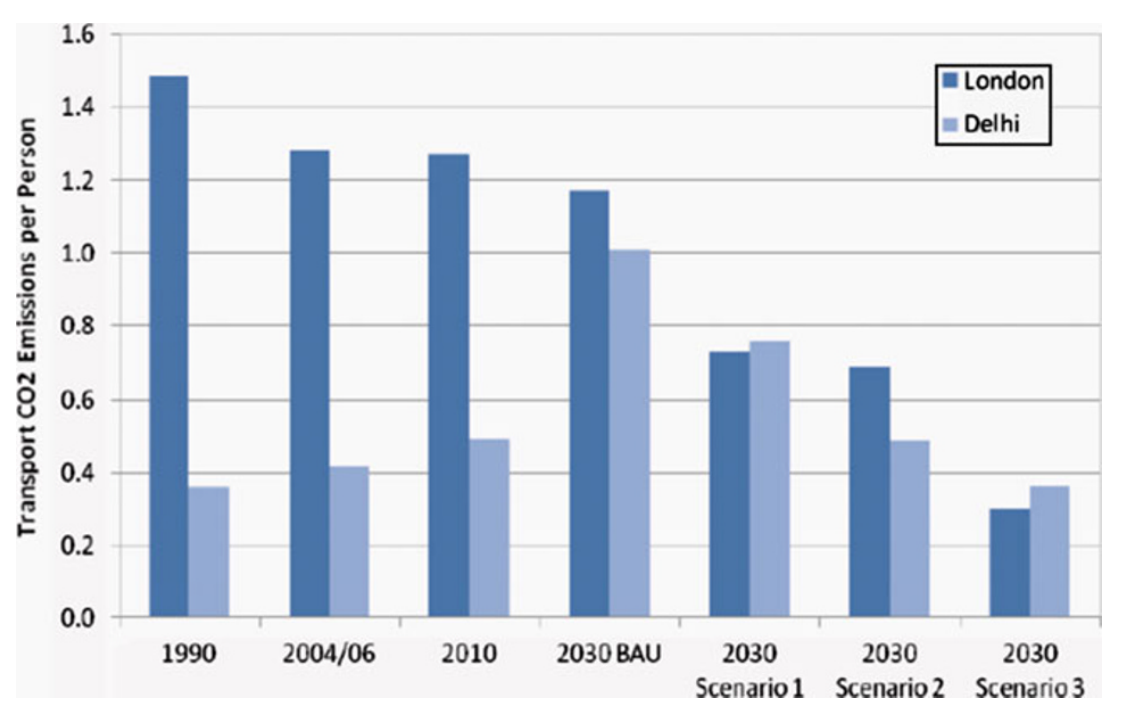


1. to achieve a considerable reduction of carbon dioxide $\left(\mathrm{CO}_{2}\right)$ emissions, both at world level, based on voluntary agreements (i.e. Kyoto Protocol) and, national and local levels based on prescriptive regulations and,

2. to address regions and cities toward a climate friendly development improving, awareness, acceptability of adopted policy measures.

By literature scenarios are "hypothetical sequences of events for the purpose of focusing attention on causal processes and decision points' [25]. In the analyzed study case, the objective is the reduction of $\mathrm{CO} 2$ emissions produced by transport sector, resulting by adoption of sustainable transport policies; whereas the events represent the progressive implementation of policies over time, aimed to incentive a more environmentally sustainable mobility.

Various scenarios can be created by variation of number, strength and duration of factors/policy measures determining different behavioural responses related to user as follows:

- Adaptive type (the citizen undergoes external actions, he/she is aware that his/her single behaviour can change his/her environmental context where lives only by an emulation process together with other individuals).

- Proactive type (the policy maker addresses the social context that manages by strategic choices - the planning process - and executive actions).

In both cases the successful of a policy or a policy package depends on the awareness that citizens have on the objective of $\mathrm{CO} 2$ reduction and in general of environmental impact reduction policies.

The policy pathways indicate the temporal ordering in which certain decisions need to be made. They are useful since, long times are required for implementing groundbreaking policies, e.g. introducing legislation, providing incentives for changing public attitude and individual behavior [35]. The use of scenarios is therefore essential to assess how the adoption of policy measures, for different type, duration and magnitude may change citizen's behavior and the environmental impact of his/her travel choices.

Scenarios can be distinguished in:

- Projective scenario: the starting point is the current situation and the future image is the result of the extrapolation of current trends [6, 30, 39, 41, 43].

- Prospective scenario (backcasting): the starting point is a possible or desirable future situation, usually described by a set of goals or targets established assuming events between the current and future situations $[1,19]$.

Each scenario is related to different mobility choices and/or different strategies. We assume that 'Business As Usual' BAU scenario is the future scenario produced by the future projection of actual factors on a long period. This scenario is the natural future evolution without external actions (factors) aiming to modify the actual trend of factors that cause carbon emission levels. Effects of actions (factors) in other future scenarios (built through a variation of number, strength and duration of factors) will be compared with the business as usual scenario. The choice of a policy to be applied is therefore based on the quantitative comparison between at least two possible scenarios of which one is ever represented by BAU. The definition of scenario is then strongly linked with the concept of factor (policy package/pathway), by which the policies are categorized and clustered as technological, regulatory, economical, planning and social; whereas its structure is related to the number, duration and magnitude of policies that the policy maker wants to adopt in the examined scenario and this produces a marked variety of different sustainable transport policies. An exhaustive analysis of policy measures was carried out in Visioning and backcasting for UK transport policy. ${ }^{1}$ Furthermore, various online sources are also available, as such as: Victoria transport policy institute online transportation demand management encyclopedia $\left(\mathrm{TDM}^{2}\right)$ and Knowledgebase on Sustainable Urban Land Use and Transport $\left(\mathrm{KONSULT}^{3}\right)$.

The described framework estimates various impacts produced by various policy measures on different co-benefit areas (time, budget, health, safety, social, and planning) by using various transport and sustainable performance indicators. Transport and Sustainable Performance Indicators (TPIs and SPIs) are standardized measures (both quantitative and qualitative) suitable for analysis in order to appraise the feasibility of a transport policy or infrastructural project and the environmental sustainability of a policy respectively; whereas Co-benefits are the benefits from policy options implemented for various reasons at the same time (IPCC 2001); also when decision makers implement a policy with a single aim and then discover that the policy resulted in additional co-benefits [22].

\subsection{Time horizon}

An important element that characterizes policies is the time horizon of lifecycle of policy measures adopted in the scenario. For example, policies that influence or change the land use (or other measures influencing firm and residential locations) changes travel behavior and need an adequately wide lifetime by which effects (benefits) of these policies can become effective. Thus, long term scenarios are

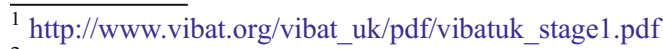

$2 \mathrm{http}: / / \mathrm{www} . \mathrm{vtpi}$.org/tdm/

${ }^{3} \mathrm{http}: / /$ www.transportconnect.net/konsult/
} 
represented in most studies and projects. In term of projection year, projects and studies analyzed highlight that 2050 and 2030 are preferred years.

Greenhouse gas emissions reduction targets for 2020 were proposed by EU that formalized its support for the Copenhagen Accord on climate change and where presented its commitments for emission reduction targets. These consist of a unilateral commitment to reduce the EU's overall emissions by $20 \%$ of 1990 levels and a conditional offer to increase this cut to $30 \%$ provided that other major emitters agree to take on their fair share of a global reduction effort.

European Commission suggests that the role of the transport sector in meeting the Kyoto targets for the European Union will be limited and is aspected that emissions from the transport sector will rise in absolute terms. Transport would then be the second largest sectoral emitter in the EU after energy. In considering deeper cuts in emissions to 2050, transport would have to play a larger role.

In the absence of sector-specific targets, IPCC [24] states that stabilization of carbon dioxide equivalence (including other GHGs) at $550 \mathrm{ppm}$ would result in a temperature change greater than $2.0^{\circ} \mathrm{C}$ [37]. Targets are normally discussed in the context of stabilizing atmospheric concentrations of CO2, which had reached $379 \mathrm{ppm}$ by 2005 on a rising trend of $1.9 \mathrm{ppm}$ per annum [24]. The most common targets are $550 \mathrm{ppm}$, which is seen as an upper bound and $450 \mathrm{ppm}$, though there remains a degree of uncertainty with respect to avoiding dangerous climatic change [6].

In coherence to $\mathrm{CO} 2$ cut emissions promoted by $\mathrm{EU}$, the overall economy wide targets for reductions in $\mathrm{CO} 2$ emissions of $60 \%$ and $80 \%$ are adopted [6]. In the 2003, UK Energy White Paper [13] accepted the need for deep cuts in $\mathrm{CO} 2$ emissions of $60 \%$ by 2050 and such a reduction may become a binding commitment if the Draft Climate Change Bill becomes law [20]. The Visioning and Backcasting for UK Transport Policy (VIBAT) project has examined the possibility of reducing UK transport $\mathrm{CO} 2$ emissions by $60 \%$ by 2030 . The study of Hickman and Banister [19] has taken and adapted one particular scenario building approach to UK transport policy over a 30 -year time horizon.

Yang et al. [43] explores options for reducing emissions in the transportation sector by $80 \%$ in the year 2050 using a scenario approach. In comparison with most other countries, the share of $\mathrm{CO} 2$ emissions emanating from the transport sector in China is comparatively low, with $6 \%$ and $8 \%$ of all $\mathrm{CO} 2$ emissions coming from the sector in 1990 and 2000, respectively. For analysis of Shiftan et al. [33], the expected scenario has a time horizon of 2030. Akerman and Hojer [1] proposed the $37 \%$ reduction of $\mathrm{CO} 2$ emissions between 1990 and 2050. An inventory of Turkish road transport emissions was calculated and the contribu- tions of road transport to global and local air pollutant emissions were examined for the year 2004 Soylu [34]. Das and Parikh [12] look at the growth in vehicles and travel demand up to 2020. Rajan [30] describes the main drivers of the US transport sector with respect to carbon emissions and current expectations of growth through 2050 without carbon-specific policies. Concerning urban areas, one study for city London [40] implements a prospective scenario for the years 2030/2050.

\subsection{Indicators}

Concerning data types transport and sustainable performance indicators required to build scenarios, most of studies and projects implement scenarios through a spreadsheet among which Bristow et al. [6], R. Hickman, D. Banister [19], Yang et al. [43], Vibat London [40]/TC-SIM [36] and EU Transport GHG: Routes to 2050? (2009), Fulton et al. [16]. In many cases, they take into account time series of data/TPIs and SPIs as traffic volumes (vehicles kilometers travelled by mode), vehicle fleet composition, average emission factor by mode, socio economic characteristic (as such as population and gross domestic product per capita).

Another relevant research is the project of the Canadian Centre for Sustainable Transportation [10] where 14 indicators were identified and the available data were either directly used as indicators, or several sets of data used to create an index (aggregating into a single value a group of indicators). Gudmundsson [17], proposed a set of indicators, defining goals, indicators and indexes. Also, he discussed on reasons of the vagueness of the sustainable mobility concept: the difficulty in identifying the critical limits for a sustainable use of the environment (environmental sustainability problem); the difficulty in defining the optimal contribution of each sector of the economy to solving each sustainability problem (economic allocation problem); the difficulty in independently assessing the sustainability of mobility, due to the links of transport activities with other activities, location choices and lifestyles (social inter-linkage problem). This means that any sustainable transportation evaluation should consider the possible impacts of mobility on the environment (e.g. noise, air and water pollution, resources depletion, habitat loss and global warming), the economy (e.g. in terms of direct and indirect transportation costs impacting on the community) and society (e.g. human health impacts, accessibility, equity, and safety problems). These three dimensions have an equal relevance for measuring progresses towards a sustainable transportation [27]. Nicolas et al. [29] applied the theme of sustainable development to urban transport and daily mobility in the city of Lyons (France). The sustainability of urban transport system is analysed by a set of indicators built through household travel survey data and 
information from minor data sources. World Business Council for Sustainable Development [42], proposed a common set of 12 indicators concerning the most important dimensions of sustainable mobility. Marsden et al. [28] identified sustainable indicators to appraise the sustainability in transport planning and policy; in this study, several dimensions have been taken into account as well economic, social and environmental indicators. Finally, Litman [26] made a critical review of transport performance indicators defining criteria for their selection.

The policy measures are here considered as our levers by which act and able to influence citizen's behaviour in order to achieve a $\mathrm{CO} 2$ emission reduction. In particular, policy measures are the specific means/actions by which policies are implemented (e.g. lower bus fares, road pricing) for purposes of transport/land use planning. Furthermore, to consider the combined effects of a set of policy measures (policy package) is often more effective rather than to consider single policy measure ones. The policy measures are grouped into policy packages. All factors have been selected by analysis of literature on studies and projects. Transport Performance Indicators (TPI) are standardized measures suitable for analysis. Obviously a specific policy measure or package will change TPIs. Indicators allow to analyze trends and impacts of scenarios. All TPIs have been selected by analysis of literature on studies and projects.

An comprehensive list of TPI to build a scenario is reported in the following Table 1. Moreover, TPIs are taken into account to implement alternative scenarios in terms of factors/policies clustered in policy packages which characterize alternative scenarios and show future trends of changed individual travel behaviors.

Data collection of TPIs is a crucial phase, but data detection and monitoring are not standardized at the city level; there is not hence a standard for data collection this aspect makes much difficult to compare different city contexts. This issue is critical and bounds the analysis of built scenarios.

\subsection{Database sources}

The emissions factors for car, bus and motorcycle can be obtained from the National Atmospheric Emissions Inventory, whereas for the private fleet composition from National Institutes of Statistics and Eurostat database can be extracted reliable data.

One of main data sources at city level is Eurostat Database Core Cities that provides various sustainable and transport performance indicators. This starting data set can be used in order to test the transferability of policy measures. For testing transferability, different cities are clustered in according to certain criteria and profiling them, in order to understand what effect has a policy on two different contexts. Data are collected at a number of different levels, namely: core cities, larger urban zones and sub-city districts (for a smaller subset of indicators). The urban audit defines a city as a legal entity (administrative concept), and delineates the 'core city' according to political and administrative boundaries; Cities are almost 450; data are averaged over 4 years from 1989 to 2010.

Another data source is the Mobility in City Database project (UITP, 2006 even if with obsolete data, reference year 2001) compiled and compared the data on urban transportation of over 100 cities around the world. The project was initiated by International Association of Public Transport (UITP) with a primary focus on sustainability and public transport. Over 200 indicators relating to passenger transport, emissions and energy and demand management were reported.

An important future data source at city level (since, it is actually not able to produce report) will be provided by Global City Indicators Program. It provides an established set of city indicators with a globally standardized methodology that allows for global comparability of city performance and knowledge sharing. ${ }^{4}$

\subsection{Policy packages}

The first comprehensive approach to appraise the effect of policy packages was Vibat for London [40], that included: Low emission vehicles; Alternative fuels; Pricing regimes; Public transport; Walking and cycling; Strategic and local urban planning; Information and communication technologies (ICT); Soft measures 'smarter choices'; Ecological driving and slower speeds; Long distance travel substitution; Freight transport.

Wang et al. [41] categorized into three groups all possible policy options: vehicle related options, road related options and fuel related options. Vehicle related options include improving engine technologies, transmission technologies, vehicle technologies. Road related options include urban planning, bus rapid transit (BRT), improving road conditions, etc. Fuel related options include renewable fuels and increased use of clean fuels.

Finally, Berrittella et al. [4] used an analytic hierarchy process (AHP) to face the question on how to select the best transport policy packages based on climate change effects of the urban transport by a means of a survey questionnaire in order to test the opinions of experts. Experts were asked to compare pair-wise the relative importance of the elements for each level. They had to compare six policy packages namely: improvement of the ecological efficiency of new vehicles; incentives for turnover of car fleet renewal; tax schemes aiming at promoting environmental-friendly transport modes;

\footnotetext{
${ }^{4}$ http://www.cityindicators.org/Default.aspx
} 
Table 1 List of TPIs to build a scenario

\begin{tabular}{ll}
\hline Macro-categories & Name of indicator \\
\hline City planning & $\begin{array}{l}\text { Population } \\
\text { Length of road per thousand inhabitants }\end{array}$ \\
& $\begin{array}{l}\text { Length of reserved public transport routes } \\
\text { per thousand inhabitants }\end{array}$ \\
& Kilometres of dedicated cycle lane per \\
thousand of inhabitants & Urban population and job density \\
Planning and development & Bus kilometres per inhabitant \\
of public transport & Tramway vehicle kilometres per inhabitant \\
Pransport demand & Percentage of daily trips by private \\
and bement & Metro vehicle kilometres per inhabitant \\
&
\end{tabular}

Percentage of daily trips by public transport

Average annual distance travelled per private passenger vehicle

Average passenger car occupancy rate

Annual private passenger vehicle kilometres per kilometre of road

Economy/Law

Private transport supply

Externalities the community in $\%$ of urban GDP

Cost of public transport for the community in $\%$ of urban GDP

Passenger cars per thousand inhabitants

Motorcycles per thousand inhabitants

Annual passenger transport fatalities
Definition

Number of inhabitants in a given city.

Length of whole road network divided by population expressed in kilometres per thousand inhabitants.

Length of whole public transport network on reserved lane divided by population expressed in kilometres per thousand inhabitants.

Level of provision of dedicated cycle lanes expressed in number of kilometres per 1,000 inhabitants

It is the ratio between the sum of the population and the number of jobs within the urban area, and the surface of the urban area

Number of busses in service for kilometres run divided by population expressed in bus kilometres per inhabitant

Number of tram vehicles in service for kilometres run divided by population expressed in tramway vehicle kilometres per inhabitant

Number of trains in service for kilometres run divided by population expressed in trains kilometres per inhabitant

Number of metro vehicles in service for kilometres run divided by population expressed in metro vehicles kilometres per inhabitant

Number of trains in service for kilometres run divided by population expressed in trains kilometres per inhabitant

The portion of travellers who choose to walk and/or to use bicycle respect to whole daily trips expressed in percentage.

The portion of travellers who choose to use private motorized vehicles (cars and motorcycle) respect to whole daily trips expressed in percentage.

The portion of travellers who choose to use public transport (rail and road modes) respect to whole daily trips expressed in percentage.

Number of kilometres travelled in private vehicles (cars and motorcycles) divided by private vehicles expressed in kilometres per private passenger vehicle

Number of people travelling in private vehicles divided by the number of private vehicle trips. This excludes transit vehicle users and walkers expressed in number of passengers per vehicle.

Number of private passenger vehicles for kilometres travelled divided by number of kilometres of road network, expressed in Vehicles Kilometres Travelled (VKT) on kilometres of road.

The value of all final goods and services produced within a territory in a given year divided by the average population for the same year.

The cost of private motorised transport for the community in percentage of urban GDP per million inhabitants

Annual $\mathrm{CO} 2$ emissions due to passenger transport per inhabitant

Number of day PM10 concentration exceeds
The cost of public transport for the community in percentage of urban GDP

Number of passenger cars divided by population expressed in number of cars per thousand inhabitants

Number of motorcycles divided by population expressed in number of motorcycles per thousand inhabitants

Number of people that are victims killed of road accidents divided by population expressed in fatalities per million inhabitants

Annual polluting emissions due to passenger transport divided by population expressed in $\mathrm{kg}$ per capita

Number of days of particulate matter PM10 concentration exceeds $50 \mu \mathrm{g} / \mathrm{m} 3$ in the urban area 
Table 1 (continued)

\begin{tabular}{|c|c|c|}
\hline Macro-categories & Name of indicator & Definition \\
\hline & $\begin{array}{l}\text { Number of serious injuries due to } \\
\text { road accidents }\end{array}$ & $\begin{array}{l}\text { Number of people that are seriously injuries of road accidents } \\
\text { divided by population expressed in number of injuries per } \\
\text { million inhabitants }\end{array}$ \\
\hline \multirow[t]{3}{*}{ Energy consumptions } & $\begin{array}{l}\text { Energy consumption per private motorised } \\
\text { passenger kilometre }\end{array}$ & $\begin{array}{l}\text { The energy consumption of private transport divided by private } \\
\text { passenger kilometres expressed in kj, kwh and ktoe (tonnes of } \\
\text { crude oil equivalent) per passenger kilometres }\end{array}$ \\
\hline & $\begin{array}{l}\text { Energy consumption per road based public } \\
\text { transport passenger kilometre (at vehicle) }\end{array}$ & $\begin{array}{l}\text { The energy consumption of road public transport divided by } \\
\text { passenger kilometres road public transport expressed in } \mathrm{kj} \text {, } \\
\text { kwh and ktoe (tonnes of crude oil equivalent) per } \\
\text { passenger kilometres }\end{array}$ \\
\hline & $\begin{array}{l}\text { Energy consumption per rail based public } \\
\text { transport passenger kilometre (at vehicle) }\end{array}$ & $\begin{array}{l}\text { The energy consumption of rail public transport divided by } \\
\text { passenger kilometres rail public transport expressed in kj, } \\
\text { kwh and ktoe (tonnes of crude oil equivalent) per } \\
\text { passenger kilometres. }\end{array}$ \\
\hline \multirow[t]{4}{*}{ Co-benefits indicators } & Coverage by PT ( $\%$ of population reached) & $\begin{array}{l}\text { The percentage of population that lives within a given distance } \\
(300 \mathrm{~m}) \text { from transit stops/stations (public transport) }\end{array}$ \\
\hline & $\begin{array}{l}\text { Affordability index (Transportation } \\
\text { Costs, } \% \text { Household Income) }\end{array}$ & $\begin{array}{l}\text { Household Transportation Costs are calculated as the sum of } \\
\text { Car Ownership Costs, Car Use Costs, and Public Transit } \\
\text { Costs. Dividing these costs by Urban Incomes shows the } \\
\text { Cost Burden placed on a Typical Household by } \\
\text { Transportation Costs. }\end{array}$ \\
\hline & Infrastructure expenditure per capita & $\begin{array}{l}\text { Per capita expenditure in } € \text { by all levels of government, } \\
\text { including government-owned companies and utilities, on } \\
\text { urban infrastructure transport services during the current } \\
\text { year. Expressed in } €\end{array}$ \\
\hline & $\begin{array}{l}\text { Cost of one private motorised } \\
\text { passenger kilometre for the traveller }\end{array}$ & $\begin{array}{l}\text { Average cost supported by traveller that use private transport } \\
\text { modes, expressed in } € \text { per motorized passenger kilometres }\end{array}$ \\
\hline
\end{tabular}

better integration between transport planning and land uses; new and better transport infrastructures; development of intelligent transport system (ITS) technologies. The criteria on the basis of which the policy packages are to be evaluated: adoption of fuels with reduced carbon content; technological improvements in the ecological efficiency of vehicles; increase in the public and multi-modal transport market share; improvements due to better mobility management systems.

\subsection{Identified gaps}

The analysis of literature has showed a strong heterogeneity of the policies adopted by various cities belonging at studied sample. Further it has highlighted the existence of a gap between studies at global/continental/national level and those at local level in term of policy measures and adopted assessment tools. In fact, policies adopted in a given geographical context (i.e. National/European) are very different from policies adopted in local context in term of economic resources, time horizon, effects and objectives. Several discussion areas are still opened and are object of scientific debate. By literature, in Particular, the identification of appropriate sectoral targets of $\mathrm{CO} 2$ reductions (in particular transport sector); the identification of the costs and benefits resulting by adoption of different policy measures/policy package/pathways; the further development and understanding of the pathways to genuinely low carbon in public transport; from a hand the analysis of synergies resulting by adoption of policy measures/policy packages; from the other hand issues relating to rebound effects, and the monitoring the effects and changes in travel behavior. The improvement of accessibility and the reduction of the need to travel — through localisation of provision and telecommunications. In the short term, it is timely to begin considering behavioural concerns as well as technology, largely because doing so may actually help overcome some of the institutional and political barriers that currently seem intractable. The exploration of the sensitivity of results to underlying assumptions. There is a clear need to raise public awareness and to get the public's active involvement in seeking solutions, and how to encourage behavioral change that can be maintained and continued over time.

The Sustainability and livability objectives (including reduced $\mathrm{CO} 2$ emissions) need to be placed at the heart of the transport and urban planning debate and made central to transport investment plans. The transferability of Policy measures/Policy packages, can have different effects if applied in cities with different development levels (GDP per capita, activities intensity/locations, motorization rate, 
mobility rate with transit), education, cultural heritage and city planning. Clustering cities in according to certain criteria and profiling them, it would be possible to understand what effect would have a policy on two different context in term of $\mathrm{CO} 2$ emission reduction and hence to overcome the transferability issue.

The analysis of co-benefits, that are the benefits from policy options implemented for various reasons at the same time [24], when decision makers implement a policy with a single aim and then discover that the policy resulted in additional co-benefits [22].

\section{Indicators and essential set of data}

TPIs are measures to assess the progress toward goals and objectives and hence these are defined in terms of goals, objectives, targets and thresholds. In choosing an essential set of TPIs, it is, also, important to avoid double-counting impacts. The selection of TPIs often involves a tradeoff between a limited set of indicators (using available data), that makes easier the collection and analysis phases, but may overlook important impacts; whereas, a larger set can be more comprehensive but have excessive data collection and analysis costs [26].

Among existing available data sources, EUROSTAT database is relatively update and owns many indicators at national level; whereas at city level has a restricted number of TPIs that can characterize a scenario of a given city. Conversely, the Mobility in City Database is much richer in term of data and is able to characterize completely a urban scenario on transportation; but nevertheless its data are quite obsolete (reference year is 2001).

Thus, the proposed list of TPIs is based on standard methodologies for data measures detected by city even for other scopes (i.e. Urban Master Plans), not strictly connected to environmental issues. In general, we have explored all aspects associated to the traditional urban mobility planning, focusing on traffic management (through strategies to reduce congestion), transportation services (public transportation supply), transportation infrastructure (the urban road networks), and adding new green mobility concepts (cycling, walking, facilities and integration with mass transit) and social, environmental, and equity issues into the planning process. Further, in the choice of TPIs we have considered a tradeoff between available data sources and the following criteria:

1. Comprehensive-Indicators should reflect various economic, social and environmental impacts, and various transport activities.

2. Data quality -Data collection practices should reflect high standards to insure that information is accurate and consistent.
3. Comparable-Data collection should be standardized so the results are suitable for comparison between various jurisdictions, times and groups. Indicators should be clearly defined.

4. Easy to understand - Indicators must useful to decisionmakers and understandable to the general public.

5. Accessible and transparent-Indicators (and the raw data they are based on) and analysis details should be available to all stakeholders [26].

We have also classified these TPIs in several categories as budget, planning \& land-use, safety, time, health \& environment and social. The choice criteria of TPIs so described would allow then to sure comparability of different city contexts and hence to assess policy pathway's effects.

\section{Budget}

1. Gross Domestic Product (GDP) per inhabitant

2. Infrastructure expenditure per capita

3. Cost of a monthly ticket for public transport (for $5-10 \mathrm{~km}$ )

\section{Planning \& Land-use}

4. Length of reserved public transport routes per thousand inhabitants

5. Tramway/Light rail/Metro/Suburban railway/Bus kilometres per inhabitant

6. Number of stops of public transport per $\mathrm{km} 2$

7. Kilometres of dedicated cycle lane per thousand of inhabitants

8. Share of journeys to work by car in Urban Audit cities-\%

9. Annual private passenger vehicle kilometres per kilometre of road

10. Percentage of daily trips on foot and by bicycle

11. Average living area in Urban Audit cities $-\mathrm{m}^{2}$ per person

12. Population density in Urban Audit cities

13. Total land area $(\mathrm{km} 2)$ according to cadastral register

14. Total population in Urban Audit cities

\section{Safety}

15. Number of deaths in road accidents per 10,000 population

16. Car thefts in Urban Audit cities-number per 1,000 inhabitants

\section{Time}

17. Registered cars in Urban Audit cities - number of cars per 1,000 inhabitants

18. Average time of journey to work 


\section{Health \& Environment}

19. Number of days particulate matter concentrations (PM10) exceeds $50 \mu \mathrm{g} / \mathrm{m}^{3}$ in Urban Audit citiesdays per year

20. Number of days ozone concentration exceeds $120 \mu \mathrm{g} / \mathrm{m}^{3}$ in Urban Audit cities - days per year

21. Energy consumption per private motorised passenger kilometre

22. Energy consumption per road based public transport passenger kilometre (at vehicle)

23. Energy consumption per rail based public transport passenger kilometre (at vehicle)

\section{Social}

24. Employment/Population (of working age) Ratio

\section{Transport sustainable index}

The sustainable development is seen inside six main areas above mentioned, nevertheless each area cannot be analyzed independently. An evaluation framework, based on indentified TPIs, has been developed in order to measure the sustainability of a given urban area. [7, 8] proposed a methodology to build a Sustainable Mobility Index in urban areas, using a Multi Criteria Analysis method for weighting selected transport and land use indicators. [5, 11, 27, 31] used similar approaches (based on multi criteria analysis) to evaluate transport sustainability at country level. Moreover Awasthi and Chauhan [2] built a Transport Sustainability Index using Analytical Hierarchy Process (AHP) for evaluating the impact of environmental friendly transport measures.

All approaches, proposed in literature are based on multi criteria analysis. These require the involvement of an experts sample, coming from several scientific areas, in order to determine weights or rankings related to TPIs and criteria of the hierarchy structure in the decision process, through pair-wise comparisons. These weights are influenced by composition and by scientific background of experts that often do not agree on judgments, determining high standard deviation values and hence an uncertainty on weights. Further all applications are site-dependent, using different sets of indicators and policies, therefore, the results cannot be transferred in other urban areas.

In these studies, there is no a direct connection with the policies or policy packages adoptable in a given urban area. In general, criteria e sub criteria are a way to decompose the sustainability concepts, and are related to generic scopes as such as: promotion of public transport, environmental comfort and safety [7]; more specific policies are reported in [27]. This procedure is very flexible in simplify the decision process, but it is less relevant when the objective is to identify a core set of TPIs. Whether from a side, the multi criteria analysis allows to test the effectiveness of policies in relation to sustainability, where the alternatives of the decision structure are the policies or policy packages; from the other side, the procedure is less effective when TPIs have to be weighted. The problem is more complex, since, two different policy packages can have some common policies and these can modify common indicators; thus choosing among an high number of indicators can produce high uncertainty on weights and these depend on the experts sample.

Furthermore, all sustainability concepts clearly affirm that economic, social and environmental dimensions must have an equal relevance for measuring progresses towards a sustainable transportation. Thus, to give a different weight to a TPI respect to another does not make sense; since, in this case, we would privilege a dimension rather than another. Therefore, the proposed approach does not give a weight to a TPI rather than another, and it is based on Euclidean distance in a vector space $\mathfrak{R}^{\mathrm{N}}$, where $\mathrm{N}$ is the number of TPIs.

In this paper, we have built a Normalized Transport Sustainability Index using identified TPIs, in order to measure and hence to compare the whole sustainability of adopted policies in different urban areas. Each TPI has been normalized in the range $(0,1)$ as follows:

$N T P I_{i, s}=\frac{T P I_{i, s}-T P I_{i, \text { min }}}{T P I_{i, \max }-T P I_{i, \text { min }}}$

where $T P I_{i, s}, T P I_{i, \max }$ and $T P I_{i, \text { min }}$ are the value of the indicator $i=1 \ldots N$, of the city $s$ and the maximum and minimum values of the indicator $i$ related to all cities, respectively. Furthermore, we have considered an hypothetical worst city, of which each $N T P I_{i}$ has values 1 or 0 when:

$N T P I_{i, w}= \begin{cases}1 & \text { if the effect of } T P I_{i} \text { is negative } \\ 0 & \text { if the effect of } T P I_{i} \text { is positive }\end{cases}$

Finally, the Normalized Transport Sustainability Index (NTSI) has calculated for each city, by using the Euclidean distance between the city $s$ and the worst city.

$T S I_{s}=\sqrt{\sum_{i}\left(N T P I_{i, s}-N T P I_{i, w}\right)^{2}}$

where $T S I_{s}$ is the Transport Sustainability Index of the city $s$ and hence normalized as follows:

$N T S I_{s}=\frac{T S I_{s}-T S I_{\min }}{T S I_{\max }-T S I_{\min }}$

The proposed methodology has been applied to 36 European Cities, for which are available more recent TPI's values. The used data source is Eurostat database, that 
Table 2 Normalized Transport Sustainable Index (NTSI) and normalized TPIs

\begin{tabular}{|c|c|c|c|c|c|c|c|c|c|c|c|c|c|}
\hline City/TPI & NTSI & ALA & $\mathrm{CT}$ & $\mathrm{E} / \mathrm{P}$ & $\mathrm{O} 3$ & PM & PD & SJC & $\mathrm{RC}$ & NDR & ATJ & NSPT & CPT \\
\hline Stockholm & 1.00 & 0.64 & 0.17 & 1.00 & 0.03 & 0.01 & 0.18 & 0.19 & 0.31 & 0.00 & 0.34 & 1.00 & 0.73 \\
\hline København & 0.98 & 0.86 & 0.20 & 0.50 & 0.06 & 0.01 & 0.25 & 0.06 & 0.00 & 0.09 & 0.19 & 0.34 & 0.37 \\
\hline Paris & 0.98 & 0.52 & 0.08 & 0.50 & 0.09 & 0.07 & 0.99 & 0.00 & 0.07 & 0.09 & 0.32 & 0.18 & 0.56 \\
\hline Genève & 0.94 & 0.68 & 0.03 & 0.50 & 0.25 & 0.00 & 0.55 & 0.19 & 0.41 & 0.00 & 0.05 & 0.19 & 0.44 \\
\hline München & 0.92 & 0.68 & 0.00 & 0.50 & 0.03 & 0.07 & 0.18 & 0.35 & 0.27 & 0.09 & 0.17 & 0.02 & 0.37 \\
\hline Oslo & 0.92 & 1.00 & 0.12 & 0.67 & 0.00 & 0.02 & 0.03 & 0.43 & 0.33 & 0.09 & 0.21 & 0.18 & 1.00 \\
\hline Barcelona & 0.91 & 0.49 & 0.19 & 0.33 & 0.07 & 0.38 & 0.76 & 0.16 & 0.33 & 0.27 & 0.19 & 0.70 & 0.19 \\
\hline Liverpool & 0.90 & 0.45 & 0.14 & 0.33 & 0.01 & 0.06 & 0.10 & 0.75 & 0.15 & 0.09 & 0.23 & 0.18 & 0.00 \\
\hline Amsterdam & 0.89 & 0.50 & 0.11 & 0.50 & 0.06 & 0.06 & 0.19 & 0.35 & 0.14 & 0.09 & 0.27 & 0.18 & 0.29 \\
\hline Manchester & 0.89 & 0.45 & 0.20 & 0.33 & 0.01 & 0.06 & 0.16 & 0.80 & 0.10 & 0.09 & 0.32 & 0.18 & 0.00 \\
\hline Helsinki & 0.87 & 0.48 & 0.31 & 0.50 & 0.03 & 0.02 & 0.12 & 0.35 & 0.28 & 0.09 & 0.17 & 0.41 & 0.38 \\
\hline London & 0.86 & 0.49 & 0.14 & 0.50 & 0.09 & 0.05 & 0.20 & 0.59 & 0.23 & 0.18 & 0.49 & 0.18 & 0.00 \\
\hline Wien & 0.86 & 0.93 & 0.08 & 0.17 & 0.34 & 0.10 & 0.16 & 0.35 & 0.36 & 0.09 & 0.14 & 0.23 & 0.50 \\
\hline Lisboa & 0.86 & 0.56 & 0.14 & 0.50 & 0.08 & 0.08 & 0.26 & 0.32 & 0.45 & 0.09 & 0.44 & 0.23 & 0.23 \\
\hline Verona & 0.85 & 0.82 & 0.11 & 0.33 & 0.00 & 0.00 & 0.03 & 0.92 & 0.78 & 0.45 & 0.03 & 0.04 & 0.19 \\
\hline Dublin & 0.85 & 0.45 & 0.33 & 0.50 & 0.00 & 0.06 & 0.16 & 0.34 & 0.35 & 0.27 & 0.22 & 0.18 & 0.19 \\
\hline Trieste & 0.84 & 0.68 & 0.07 & 0.33 & 0.17 & 0.00 & 0.09 & 0.45 & 0.63 & 0.45 & 0.02 & 0.43 & 0.32 \\
\hline Berlin & 0.84 & 0.63 & 0.05 & 0.33 & 0.23 & 0.05 & 0.16 & 0.42 & 0.14 & 0.09 & 0.28 & 0.01 & 0.79 \\
\hline Frankfurt & 0.83 & 0.66 & 0.01 & 0.50 & 0.39 & 0.04 & 0.10 & 0.39 & 0.20 & 0.27 & 0.17 & 0.00 & 0.67 \\
\hline Rotterdam & 0.81 & 0.56 & 0.16 & 0.33 & 0.03 & 0.06 & 0.11 & 0.61 & 0.22 & 0.27 & 0.27 & 0.18 & 0.58 \\
\hline Firenze & 0.81 & 0.72 & 0.26 & 0.50 & 0.62 & 0.15 & 0.14 & 0.41 & 0.66 & 0.27 & 0.08 & 0.70 & 0.32 \\
\hline Genova & 0.80 & 0.61 & 0.28 & 0.50 & 0.56 & 0.04 & 0.09 & 0.28 & 0.51 & 0.18 & 0.15 & 0.23 & 0.33 \\
\hline Madrid & 0.79 & 0.45 & 0.11 & 0.33 & 0.31 & 0.07 & 0.22 & 0.48 & 0.54 & 0.27 & 0.29 & 0.50 & 0.32 \\
\hline Trento & 0.78 & 0.65 & 0.02 & 0.50 & 0.58 & 0.13 & 0.00 & 0.85 & 0.74 & 0.36 & 0.00 & 0.01 & 0.19 \\
\hline Bruxelles & 0.77 & 0.55 & 0.10 & 0.17 & 0.25 & 0.15 & 0.28 & 0.60 & 0.55 & 0.18 & 0.30 & 0.33 & 0.36 \\
\hline Lyon & 0.76 & 0.54 & 0.21 & 0.33 & 0.20 & 0.16 & 0.08 & 0.93 & 0.47 & 0.18 & 0.11 & 0.18 & 0.46 \\
\hline Athina & 0.74 & 0.41 & 0.19 & 0.33 & 0.31 & 1.00 & 1.00 & 0.59 & 0.55 & 0.55 & 0.14 & 0.18 & 0.32 \\
\hline Bologna & 0.72 & 0.72 & 0.32 & 0.67 & 0.93 & 0.29 & 0.10 & 0.63 & 0.64 & 0.36 & 0.08 & 0.22 & 0.28 \\
\hline Napoli & 0.71 & 0.22 & 0.48 & 0.33 & 0.17 & 0.36 & 0.38 & 0.59 & 0.72 & 0.36 & 0.19 & 0.65 & 0.33 \\
\hline Palermo & 0.71 & 0.43 & 0.48 & 0.33 & 0.18 & 0.04 & 0.18 & 0.82 & 0.77 & 0.45 & 0.06 & 0.35 & 0.49 \\
\hline Budapest & 0.70 & 0.00 & 0.09 & 0.50 & 0.37 & 0.22 & 0.13 & 0.59 & 0.27 & 0.36 & 1.00 & 0.20 & 0.29 \\
\hline Milano & 0.69 & 0.62 & 0.47 & 0.67 & 0.81 & 0.59 & 0.33 & 0.44 & 0.69 & 0.45 & 0.20 & 0.64 & 0.32 \\
\hline Torino & 0.68 & 0.54 & 0.29 & 0.33 & 1.00 & 0.61 & 0.32 & 0.74 & 0.84 & 0.27 & 0.27 & 0.81 & 0.28 \\
\hline Roma & 0.65 & 0.51 & 0.47 & 0.50 & 0.22 & 0.18 & 0.07 & 0.66 & 1.00 & 0.55 & 0.28 & 0.10 & 0.46 \\
\hline Catania & 0.56 & 0.39 & 1.00 & 0.00 & 0.69 & 0.10 & 0.05 & 1.00 & 0.98 & 1.00 & 0.06 & 0.19 & 0.32 \\
\hline
\end{tabular}

$A L A$ Average living area;

CT Car thefts;

E/P Employment/Population (of working age) Ratio;

$O 3$ Number of days ozone concentration exceeds $120 \mu \mathrm{g} / \mathrm{m}^{3}$;

$P M$ Number of days particulate matter concentrations (PM10) exceeds $50 \mu \mathrm{g} / \mathrm{m}^{3}$;

$P D$ Population density;

$S J C$ Share of journeys to work by car;

$R C$ Registered cars;

$N D R$ Number of deaths in road accidents;

$A T J$ Average time of journey to work;

NSPT Number of stops of public transport per $\mathrm{km}^{2}$;

$C P T$ Cost of a monthly ticket for public transport; 


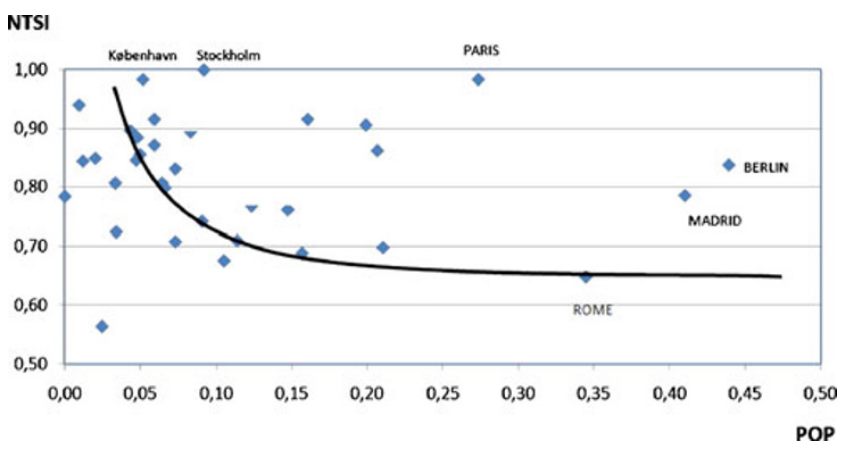

Fig. 4 The NTSI in term of population

contains available TPIs for year 2007-2010. The results of the carried out analysis are reported in Table 2, whereas Figs. 4 and 5 show the scatter plot of NTSI in term of population and land city area respectively, excluding London as outlier (London is a mega city in term of population and land city area).

Finally, for several European cities the NTSI values have been linked with policies adopted by each city (Table 3), taking into account some policy packages (as such: urban planning \& transport, transport demand management, development of public transport and organization \& integration). Clearly, the effects of each policy depend on the intensity, the duration and the particular adopted policy action; nevertheless some relevant outcomes and lessons can be achieved by the carried out analysis.

First of all, it should be noted that an high value of NTSI is associated in general to small-medium cities in term both population and urban area. This aspect confirms that sustainable transport policies are more effective in smallmedium cities, where is easier to guarantee a base mobility by using public transport, obviously, in bounds of available budget of administration. Same results can be achieved considering NTSI in term of extension urban area, where we can note that cities interested by sprawl phenomenon (i.e. Rome) have low sustainability; although Paris has over 2 million of inhabitants, it has a compact urban structure, and a good public transport supply that reduce the externalities due to car private.

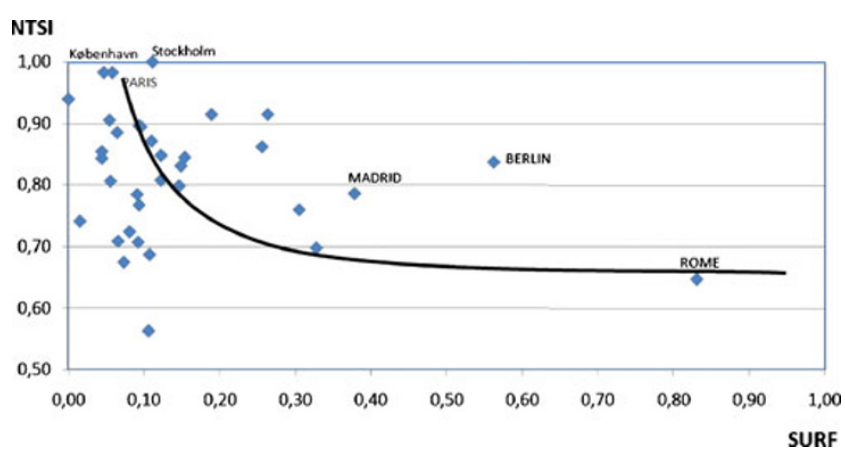

Fig. 5 The NTSI in term of land city area
All cities that have adopted policy measures, from a side, to control the urban sprawl (and hence its dimension toward a compact city versus polycentric city), and from the other side, to manage the urban transport demand (and hence flows on the network and the modal shift) have a more sustainable mobility (Table 3). The compact design assumes an extensive development and utilization of public transport, made viable through high density development implying a more efficient transport system. It is ideal for the public transport (high traffic volumes on few main lines). The polycentric urban design follows a more natural extension, with the most of people living within large towns, and still heavily dependent by their own private transport. It is affected by increased costs of providing public transport and the basic mobility.

\section{Conclusion}

There are difficulties, on a theoretical as well as on a practical level, related to the implementation of policy measures in the city context. Every application is site dependent and uses specific set of indicators. The lack of homogeneity in detection, measure, store and monitoring of standardized performance indictors often does not permit to compare different city contexts. In such context, a standardized set of performance indicators would allow to analyze quantitatively the effects of adopted policy measures.

Data collection of TPIs is a crucial phase, but data detection and monitoring are not standardized at the city level; there is not hence a standard for data collection this aspect makes much difficult to compare different city contexts. This issue is critical and bounds the analysis of built scenarios. The definition of a essential set of indicators should be developed at least at European Level, providing an European standard to ensure the full comparability of different policies.

The paper answers to some of these questions providing: a specific set of sustainable and transport performance indicators to evaluate effects of policy measures; and a comparative analysis of different European cities in terms of development, sustainability and infrastructures, by using transport performance indicators.

For this task, a Normalized Transport Sustainability Index has been built using identified TPIs, in order to measure and hence to compare the whole sustainability of adopted policies in different urban areas. The NTSI has been calculated by using the Euclidean distance between the city $i$ and the worst city. This is an hypothetical city, of which each $N T P I_{i}$ has values 1 or 0 when the indicator has negative or positive effect on the sustainability respectively. 


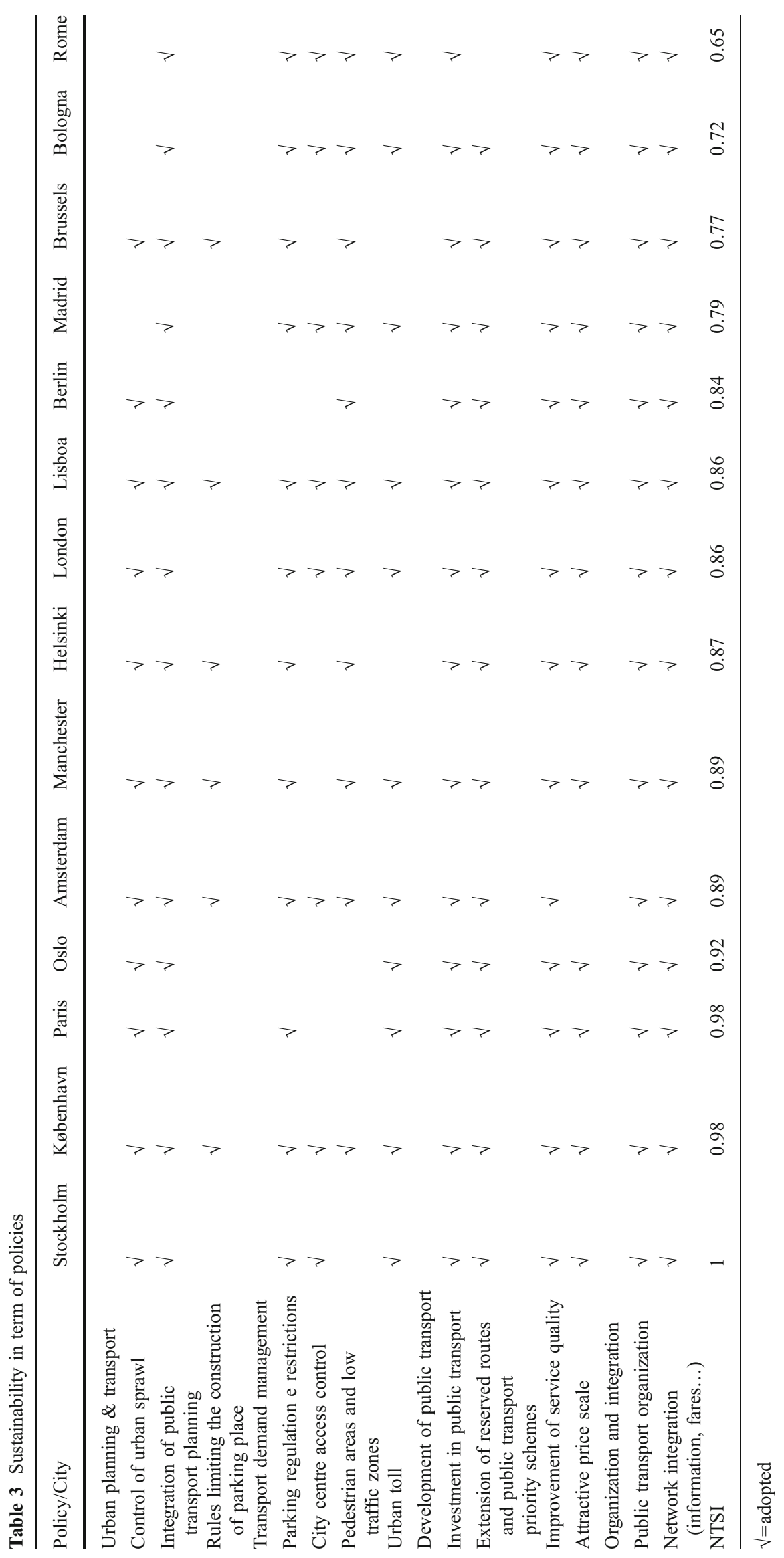


Conversely to the methodological approach proposed in literature, based on Multi Criteria Analysis giving different weights (affected by uncertainty) to TPIs, our methodological approach is based on Euclidean distance in a vector space $\mathfrak{R}^{\mathrm{N}}$, where $\mathrm{N}$ is the number of TPIs. The main reason of this choice is that all sustainability concepts clearly require that economic, social and environmental dimensions must have an equal relevance for measuring progresses towards a sustainable transportation. Thus, to give a different weight to a TPI respect to another does not make sense; since, in this case, we would privilege a dimension rather than another. The defined NTSI is, therefore, an objective measure of the urban transport sustainability, whereas proposed indexes are subjective measures dependent by weights provided by an experts sample. Further this approach can be implemented by decision maker, when the importance of a policy respect to other is unknown, in a preliminary phase of design of sustainable policies, before of an approaches based on Multi Criteria Analysis aimed to test the effects of a set of policies or to choose the best policies [4].

The outcomes of the comparative analysis are consistent and so summarized. An high value of sustainability is associated in general to small-medium cities in term both population and urban area; nevertheless, for large cities, the adoption of policy measures, from a side, to control the urban sprawl, from the other side, to manage the urban transport demand with an adequate public transport development allows to achieve a more sustainable mobility (i.e. London).

Open Access This article is distributed under the terms of the Creative Commons Attribution License which permits any use, distribution and reproduction in any medium, provided the original author(s) and source are credited.

\section{References}

1. Akerman J, Hojer M (2006) How much transport can the climate stand? Sweden on a sustainable path in 2050. Energy Policy 34:1944-1957

2. Awasthi A, Chauhan SS (2011) Using AHP and Dempster-Shafer theory for evaluatng sustainable transport solutions. Environ Model Softw 26:787-796

3. Banister D (2008) The sustainable mobility paradigm. Transp Policy 15:73-80

4. Berrittella M, Certa A, Enea M, Zito P (2008) Transport policy and climate change: how to decide when experts disagree. Environ Sci Policy 2:307-314

5. Bojkovic N, Anic I, Pejcic-Tarle S (2010) One solution for crosscountry transport-sustainability evaluation using a modified ELECTRE method. Ecol Econ 69:1176-1186

6. Bristow A, Tight MR, Pridmore A, May AD (2008) Developing pathway to low carbon land based passenger transport in Great Britain by 2050. Energy Policy 36:3427-3435
7. Campos VBG, Ramos RAR, de Miranda D, Correia S (2009) Multi-criteria analysis procedure for sustainable mobility evaluation in urban areas. J Adv Transp 43(4):371-390

8. Campos VB, Ramos RAR (2005) Sustainable mobility evaluation in urban areas. In: Jaszkiewicz A et al (eds) Advanced OR and AI methods in transportation. Poznan University of Technology, Poznan, pp 172-177

9. CATCH (2009) Carbon aware travel choice project website: http:// www.carbonaware.eu/

10. CST (2003) Sustainable transportation performance indicators project, centre for sustainable transportation website http://cst. uwinnipeg.ca/completed.html\#indicators

11. da Silva RAN, da Silva M, Macedo MH (2008) Multiple view of sustainable urban mobility: the case of Brazil. Transp Policy 15:350-360

12. Das A, Parikh J (2004) Transport scenarios in two metropolitan cities in India: Delhi and Mumbai. Energy Convers Manag 45:2603-2625

13. Department of Trade and Industry (2003) Energy white paper commitments, website http://dti.gov.uk/energy/sepn/secondannualreport commitments.pdf

14. EEA (2008) Greenhouse gas emission trends and projections in Europe 2008, Report No 5/2008, website http://www.eea.europa. eu/publications/eea_report_2008_5

15. EPA (2009) U.S. greenhouse gas inventory, environmental protection agency, 2009, website http://www.epa.gov/climatechange/emissions/ usgginventory.html

16. Fulton L, Cazzola P, Cuenot F (2009) IEA Mobility Model (MoMo) and its use in the ETP 2008. Energy Policy 37:3758-3768

17. Gudmundsson H (2003) Making concepts matter: sustainable mobility and indicator systems in transport policy. Int Soc Sci J 55 (No. 2, Issue 176):199-217

18. Hickman R, Ashiru O, Banister D (2009) Transition to low carbon transport futures. Strategic conversations fro London and Delhi. European Transport Conference. pp. 1-17

19. Hickman R, Banister D (2007) Looking over the horizon: transport and reduced CO2 emissions in the UK by 2030. Transp Policy 14:377-387

20. HM Government (2007) Draft climate change bill, website http:// www.officialdocuments.gov.uk/document/cm70/7040/7040.pdf

21. IEA (2007) International Energy Agency (IEA) database vol. 2007, CO2 emissions from fuel combustion website/http:// caliban. sourceoecd.org $/ \mathrm{vl}=213511 / \mathrm{cl}=25 / \mathrm{nw}=1 / \mathrm{rpsv} / \mathrm{iea}$ database.htmS

22. IES Handbook (2004) The integrated environmental strategies handbook EPA 2004 website http://www.epa.gov/ies/pdf/handbook/ies_maintext_508.pdf

23. INTRA-SIM Oxfordshire project website http://www.zupastudio. com/projects/intrasim/intrasim_ox.shtml

24. IPCC (2007) Fourth assessment report on climate change, 2007, website http://www.ipcc.ch/pdf/assessment-report/ar4/syr/ ar4 syr.pdf

25. Kahn HA, Wiener A (1967) The year 2000: a framework for speculation. Macmillan, New York

26. Litman, Todd (2011) Well measured: developing indicators for comprehensive and sustainable transport planning, Victoria Transport Policy Institute (www.vtpi.org); at www.vtpi.org/ wellmeas.pdf

27. Mameli F, Marletto G (2009) Can national survey data be used to select a core set of indicators for monitoring the sustainability of urban mobility policies? Working paper, Centro Ricerche Economiche Nord Sud (CRENOS) pp. 1-32

28. Marsden G, Kelly C, Nellthorp J, Lucas K and Brookes M (2005) A framework for the appraisal of sustainability in transport, Project Report, http://www.its.leeds.ac.uk/projects/sustainability/ index.html 
29. Nicolas JP, Pochet P, Poimboeuf H (2003) Towards sustainable mobility indicators: application to the lyons conurbation. Transp Policy 10:197-208

30. Rajan SC (2006) Climate change dilemma: technology, social change or both? An examination of long term transport policy choices in the United States. Energy Policy 34:664-679

31. Rassafi AA, Vaziri M (2005) Sustainable transport indicators: definition and integration. Int J Environ Sci Technol 2(1):83-96

32. Rijkee X, van Essen H (2010) EU transport GHG: routes to 2050? - review of projections and scenarios for transport in 2050 (REPORT V), pp. 1-45, website http:/www.eutransportghg2050.eu/ $\mathrm{cms} /$

33. Shiftan Y, Kaplan S, Hakkert S (2003) Scenario building as a tool for planning a sustainable transportation system. Transp Res Part D 8:323-342

34. Soylu S (2007) Estimation of Turkish road transport emissions. Energy Policy 35:4088-4094

35. Taeihagh A, Alcántara RB, Millican C (2009) Development of a novel framework for the design of transport policies to achieve environmental targets. Comput Chem Eng 33:1531-1545

36. TC-SIM (2007) UrbanBuzz programme, website http://www. vibat.org/vibat_ldn/tcsim.shtml
37. Tight MR, Bristow AL, Pridmore A, May AD (2005) What is a sustainable level of $\mathrm{CO} 2$ emissions from transport activity in the UK in 2050? Transp Policy 12:235-244

38. Timilsina GR, Ashish S (2009) Transport sector CO2 emissions growth in Asia: underlying factors and policy options. Energy Policy 37:4523-4539

39. TREMOVE (1997) A policy assessment model to study the effects of different transport and environment policies on the transport sector for all European countries project website http:// www.tremove.org/

40. Visioning and backcasting for transport policy in London project (Vibat for London 2007), website http://www.vibat.org/

41. Wang C, Cai W, Chen J (2007) CO2 mitigation scenarios in China's road transport sector. Energy Convers Manag 48:2110-2118

42. World Business Council for Sustainable Development (2004) Mobility 2030: meeting the challenges to sustainability, The Sustainable Mobility Project, Report 2004, website www. wbcsd.org

43. Yang C, McCollum D, McCarthy R, Leighty W (2009) Meeting an $80 \%$ reduction in greenhouse gas emissions from transportation by 2050: a case study in California. Transp Res Part D 14:147-156 